WellBeing International

WBI Studies Repository

4-9-1994

\title{
Animal Protection and Medical Science
}

David O. Wiebers

Jennifer Leaning

Roger D. White

Follow this and additional works at: https://www.wellbeingintlstudiesrepository.org/acwp_arte

Part of the Animal Experimentation and Research Commons, Animal Studies Commons, and the Other Anthropology Commons

\section{Recommended Citation}

Wiebers, D. O., Leaning, J., \& White, R. D. (1994). Animal protection and medical science. The Lancet, 343(8902), 902-4.

This material is brought to you for free and open access by WellBeing International. It has been accepted for inclusion by an authorized administrator of the WBI Studies Repository. For more information, please contact wbisr-info@wellbeingintl.org.

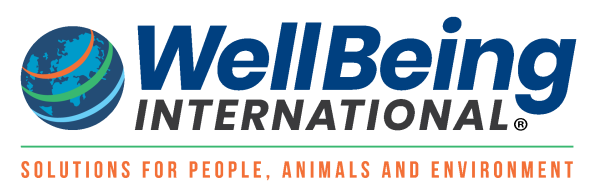




\title{
Animal protection and medical science
}

\author{
David O. Wiebers, ${ }^{1}$ Jennifer Leaning, ${ }^{2}$ Roger D. White ${ }^{1}$ \\ ${ }^{1}$ Rochester, Minnesota, USA \\ ${ }^{2}$ Boston, Massachusetts, USA
}

CITATION

Wiebers, D. O., Leaning, J., \& White, R. D. (1994). Animal protection and medical science. The Lancet, 343(8902), 902-4.

\section{Animal protection and medical science}

Over the past decade, the debate concerning animal use in biomedical research, education, and testing has contributed to an environment of public posturing on both sides. Many in the medical and animalprotection communities have come to view one another as adversaries with hopelessly different goals.

In the face of rapid and substantial increases in public concern over the wellbeing of animals, many in the medical community have sought to fend off what they see as an increasingly threatening social trend. Those who have spoken out on behalf of various medical organisations or institutions have generally been avid animal-research advocates. ${ }^{1-5}$ Those with dissenting viewpoints within the medical community have been labelled dangerous and have been discouraged from advancing their opinions publiclydevelopments contrary to the spirit of science.

Faced with this one-sided argument the broader medical community has failed to call attention to various untenable positions of many animal-research advocates, who have sought exclusive representation of medical science in this debate. Uncritical acceptance of these positions could substantially damage the credibility of medical science, fuel the fires of those seeking to characterise physicians as self-serving, self-righteous individuals who value their scientific careers above all else, and ultimately lead the public to withdraw control of this aspect of medical science from physicians.

\section{Us versus them}

The most sweeping argument is that efforts to advance animal protection and human health are incompatible. Many exponents seek to reduce the situation to an us or them competition-human beings versus animals. ${ }^{5,6}$ The more fully articulated argument, advanced or implied by organisations and individuals within the medical community, is that any modification in animal use to enhance animal protection would undermine the future of medical science and thus threaten human health.

This is not the case. Animal-protection organisations can and should have a positive impact on the scientific community (and on society) by serving as a stimulus for change that would otherwise be unlikely to occur. ${ }^{7}$ If the stated concerns of medical science about the wellbeing of animals represent more than empty words, we should welcome suggested changes and delight in discovering new ways to advance animal protection in medicine. 
Despite some modest advances over the past few decades, generally occurring despite objections from the medical establishment, ${ }^{7-9}$ there continue to be major opportunities to improve the status quo, incorporating the three Rs, ${ }^{10}$ refinement of techniques, reduction in the numbers of animals used, and replacement of animal methods with other techniques. We submit that all three initiatives could proceed without any ill-effect on human health.

\section{All medical advances derive from animal research}

Another assertion from animal research advocates states that all or virtually all major medical advances and biomedical knowledge of significance derives from research using animals. If one accepts these notions, then animal research might appear to be the only means we have to advance medical science. Such a perspective, however, reflects a considerable bias in interpreting the past and implies a diminished capacity to discern and select the most appropriate measures for advancing human health care in the future.

\section{All animal research is valuable}

Yet another argument that has been added to the debate is that virtually all animal research-based science, approved and conducted under current systems and regulations, is inherently valuable. Gluck and Kubacki ${ }^{11}$ have pointed out: "As biomedical researchers we have tended to identify ourselves and our work with the finest exemplars of animal research. This is natural enough and can be seen as an attempt to self-motivate to a higher level of professional performance. But when it is made to appear that these examples are typical of the quality and usefulness of animal research, we have entered the domain of strict strategic action. Worst of all, this dogma may become something we ourselves begin to believe ... The evidence is clear that all is not as well as we wish or as well as we represent to the public".

With over 8000 biomedical research journals publishing over 1 million articles per year, JAMA deputy editor Drummond Rennie ${ }^{12}$ has commented, "There seems to be no study too fragmented, no hypothesis too trivial ... no design too warped, no methodology too bungled ... no conclusions too trifling ... for a paper to end up in print". Some portion of this trivial and unsound research (with many such projects that are never published) involves animal research. Gluck and Kubacki also observed: ${ }^{11}$ "It is one thing to waste our own time and effort and the time of other scientists, but it is another thing to waste the lives of other animals for the sake of a longer vita or thicker progress report".

\section{Serendipity in science}

Serendipity in scientific discovery is frequently used to justify the status quo in animal research. We argue that in the biomedical field, most high-quality basic science and most clinical advances have come from directed hypotheses and carefully conceived experimental designs. Dixon addresses this point poignantly: "Where the blind empiricist will stumble from one question to the next, and the scientist with the accountant mentality will deploy a massive induction-based experiment (which may somehow throw up the result he is looking for), the top-class creative thinker designs a single crucial experiment that decides absolutely between one hypothesis and another". ${ }^{13}$

Furthermore, in that subset of science where the lives and welfare of other beings are at stake, it is reasonable and humane to call for parsimony in animal use. It should not be considered proper scientific practice or method to support work in animals that pursues random association or data collection from various undirected activities undertaken with little or no preconception of how the data eventually obtained might relate to improving human or animal health. 


\section{There are no alternatives, only adjuncts}

Many animal-research advocates have recently enlisted another argument. They would abandon the term alternatives, and instead endorse other techniques as adjuncts to animal research. The term alternatives arouses the fear that conceding any replacement for animal research might lead to widespread replacement. This reluctance to look more broadly at the full rahge of research methods and designs ignores the fact that for much research, better science dictates a shift to cellular, molecular, and mathematical systems.

Although there remain many circumstances in which we cannot produce information without using live animals, we need to be more open to the possibility that a particular piece of information derived from animal research may not be needed to solve the clinical problem. In this context, the alternatives concept expands to focus on the scientific strategy needed to reach an end-result rather than on the search for individual data elements.

\section{Medical science and the public debate}

Soon, and it would be prudent to begin now, all medical participants in this debate need to cease from attempts to polarise the issues. The question requires discussion based on merits, not distorted by the rhetoric or tactics of fear. A recent article ${ }^{5}$ accused the animal-protection movement of frightening the public, and attempted to persuade the medical world that physical attacks are tactics that are frequently used by the animal protection community. Such instances are rare and not part of the agenda of the vast majority of animal protectionists who have no interest in damaging science, scientists, or any living thing. ${ }^{14}$

Animal-research advocates have themselves on occasion sought to frighten the public with statements to the effect that medical science will be severely damaged or halted or millions of human lives will be lost in response to suggested humane modifications in research policies. ${ }^{2,4}$ In reality, neither science nor the world will come to a tragic end by attempting to refine, reduce, and replace part or all of the use of animals in biomedical research, education, and testing.

It would be lamentable if being a physician or scientist meant that one could not care deeply about the welfare of sentient beings other than human beings. To those in the animal-protection community, a deep caring implies more than lip service. It implies placing high priorities on securing humane conditions for animals even in the face of substantial extra cost and looking carefully and critically at projects and areas in which animal research is highly unlikely to benefit health, or is grossly inhumane, and a commitment to call for the cessation of those projects. It implies placing a high priority on the development of alternatives to animal research, including the creation of incentives for such approaches and the expenditure of greater time and resources.

For the medical community to respond with reflexive, parochial attacks, based in part on untenable positions is not in the long-term interests of science. Such attacks enable the medical community to deny the existence of any problems with the status quo.

Society will be better off when the biomedical community recognises the animal-protection community as an extension of itself-allowing the alleviation of unnecessary suffering and death to extend to beings other 
than humans. Perhaps then we may realise the day when scientific investigators are moved to direct more of their efforts towards developing innovative and effective alternatives to animal use rather than innovative and effective ways to avoid changing the status quo.

\section{References}

1. Cohen C. The case for the use of animals in biomedical research. N Engl J Med 1986; 315: 86570.

2. Smith SJ, Hendee WR. Animals in research. JAMA 1988; 259: 2007-8.

3. Woolsey TA. The domination of knowledge by ignorance: politics and regulation of animal research for diagnosis and treatment of disease. Circulation 1988; 77: 1197-202.

4. Johnson D. Animal rights and human lives: time for scientists to right the balance. Psychol Sci 1990; 1: 213-16.

5. Pardes H, West A, Pincus HA. Physicians and the animal-rights movement. N Engl J Med 1991; 324: 1640-43.

6. VonNoorden GK. In defense of animal research. Am J Ophthalmol 1991; 111:367-69.

7. Animal Welfare Act. 7 USC 2131-2157 and CFR Ch 1 (1990).

8. Visscher MB. The congress and animal experimentation. JAMA 1966; 196: 101-2.

9. Lubaton S. Animal advocates win court ruling. New York Times, Feb 25, 1993.

10. Russell WMS, Burch RL. The principles of humane experimental technique. London: Methuen, 1959.

11. Gluck JP, Kubacki SR. Animals in biomedical research: the undermining effect of the rhetoric of the besieged. Ethics Behav 1991; 2: 157-73.

12. Rennie D: editors and authors. JAMA 1989; 261: 2543-45.

13. Dixon B. What is science for? London: Penguin Books, 1976.

14. Kullberg JF, Hoyt JA, Thornton GW. Joint resolutions for the 1990s by American animal protection organizations. Ne'IJJ York Times, Jan 29, 1991. 